\title{
Acção colectiva, protesto e cidadania
}

José Manuel Mendes e Ana Maria Seixas

\section{(2) OpenEdition}

\section{Journals}

Edição electrónica

URL: http://journals.openedition.org/rccs/976

DOI: $10.4000 /$ rccs.976

ISSN: 2182-7435

Editora

Centro de Estudos Sociais da Universidade de Coimbra

Edição impressa

Data de publição: 1 outubro 2005

Paginação: 03-06

ISSN: 0254-1106

Refêrencia eletrónica

José Manuel Mendes e Ana Maria Seixas, «Acção colectiva, protesto e cidadania », Revista Crítica de

Ciências Sociais [Online], 72 | 2005, posto online no dia 01 outubro 2012, consultado o 21 setembro 2020. URL : http://journals.openedition.org/rccs/976 ; DOI : https://doi.org/10.4000/rccs.976 


\section{Acção colectiva, protesto e cidadania}

Ao organizar um número da Revista Crítica de Ciências Sociais sobre a temática vasta e heterogénea da acção colectiva, procurámos apresentar um conjunto de contribuições críticas que, indo para além da simples sintese, pudessem fornecer instrumentos para se perceber as principais mudanças nas formas de mobilização e participação políticas na actualidade. Trata-se de discutir e de problematizar o conceito de democracia, no sentido amplo de república e de construção da coisa pública e do bem comum, numa lógica trans-escalar e sem valorização prévia de um lugar privilegiado de análise. Não pressupondo a crise do político, o que se pretende é revelar outras formas de fazer política, fora dos contextos político-partidários e das instituições.

Tomando como ponto de partida as propostas teóricas em torno dos novos movimentos sociais, foi nossa intenção trazer à reflexão novas práticas e novos reportórios de acção-aquilo a que alguns autores chamam novos movimentos de protesto ou democracia de manifestação - que alargam o campo da cidadania a direitos que poderíamos designar de quarta geração, por implicarem uma componente expressiva e de reconhecimento, no oscilar constante e imprevisto entre as aspirações e as emoções pessoais e práticas colectivas inovadoras, muitas vezes efémeras, outras de mais longa duração. E é de democracia que se trata, apesar das profundas mudanças históricas dos conteúdos deste significante, porque é da capacidade de vivermos juntos que estamos a falar, da necessidade de uma pertença para além do individualismo e aquém das tendências uniformizadoras da globalização hegemónica, extravasando ou contornando a noção clássica de Estado-nação. E isto porque o viver juntos implica necessariamente um controlo de quem detém o poder, num objectivo alargado e pleno de democracia participativa, assente no dialogismo e na presença em igualdade de todos os corpos e vozes.

Assim, aos conceitos de acção colectiva, de protesto e de democracia associa-se uma noção abrangente e impossivelmente universal e hospitaleira de cidadania. É certo, uma cidadania de destino e imperfeita, mas que se realiza e constrói pela presença permanente de acções recalcitrantes, resistentes, de reivindicação de direitos básicos como o alojamento, a saúde, o trabalho, a educação, até ao reconhecimento de outras maneiras de ser e de fazer. 
Os movimentos sociais, os protestos e as novas possibilidades de produzir cidadania devem ser lidos como reveladores de democratização das sociedades. Indo para além das análises unilaterais de participação política, convencional ou não-convencional, tomamos as aç̧ões de protesto e de reivindicação como indicadores e como protagonistas inerentes a todo o processo democrático. Os protestos e as reivindicações não são formas patológicas de acção política, mas formas expressivas de realização de cidadania em contexto democrático.

A construção dos novos espaços públicos potenciadores da produção de cidadanias conflituantes e emancipadoras obriga a um trabalho de reflexão acrescido por parte dos cientistas sociais e dos investigadores. Alguns pressupostos são de fixar nessa tarefa: recusa de imputar causas, lógicas ou tendências a priori; tomar as pessoas como participantes de pleno direito e não como meros títeres ao sabor de manipulações; não projectar tipos-ideais ou referenciais abstractos de democracia e de cidadania; não desvalorizar a lenta urdidura do bem comum a que se dedicam as pessoas, tentando apreender exaustivamente as suas justificações e as suas críticas do social; por último, não utilizar conceitos vagos como populismo, cesarismo, caciquismo, para explicar ou legitimar estilos de liderança ou putativos inconscientes de acção.

Desta posição epistemológica e metodológica, emergem narrativas e bistórias que permitem pensar alternativas, outras possiveis realidades e, sem transcendências, a imanência das aç̧ôes de protestos transformadoras, mesmo que efémeras ou pontuais. A presença na rua ou em outro qualquer espaço público abre sempre uma nova perspectiva sobre o politico, um sobressalto, um questionamento dos poderes e das estruturas estabelecidas, um acontecimento que pode produzir novas subjectividades pessoais e colectivas, novos registos e novos regimes de definição do que é a verdade.

O artigo de Boaventura de Sousa Santos parte de uma crítica da governação neoliberal para afirmar o potencial da construção de uma sociedade civil global assente numa política da legalidade cosmopolita subalterna e na produção de esferas públicas não-estatais. A concretização de uma globalização contra-hegemónica pode ser apreendida através das contradições e das potencialidades do Fórum Social Mundial. Após as crises da legitimidade e da governabilidade, a governação impôs-se como a matriz política da globalização neoliberal e da regulação social pós-estatal. Nesta globalização hegemónica dois actores tornam-se invisiveis ou não-existentes: o Estado e os excluídos. Como consequência, duas tensões percorrem transversalmente a problemática da governação: a redistribuição social e a questão do reconbecimento da diferença.

Estas contradições e ambiguidades estarão na origem da reflexão e na construção de espaços e de práticas alternativos dos múltiplos movimentos 
e tendências que se congregam no Fórum Social Mundial. Como utopia crítica e como uma forma de relacionamento não-herárquica, emancipadora e participativa, projectada numa dimensão trans-escalar, o Fórum abre a possibilidade de se pensar um outro mundo mais justo e igual e incorporando as inelutáveis diferenças que obrigam a aceitar, e não a tolerar, o outro como alteridade desafiadora.

O texto de Richard Flacks inscreve-se num registo bastante distinto. Atendo-se ao contexto euro-americano, é-nos apresentada uma crítica contundente do modelo teórico dominante do estudo dos novos movimentos sociais (modelo de Tilly, McAdam e Tarrow). Flacks argumenta que os proponentes deste modelo o apresentam como uma teoria, quando, na realidade, se trata de simples explicações post factum, que têm relevância somente no confinado mundo académico. Se os estudos, em número quase infinito, sobre os novos movimentos sociais não são pertinentes para os activistas, se não transportam qualquer contributo para a emancipação social, se não nos informam sobre as biografias e as trajectórias dos activistas ou sobre as componentes identitárias $e$ as lógicas de recrutamento, servirão então para quê?

Em contrapartida, Richard Flacks propõe um retorno crítico a Karl Marx, a uma teoria pós-marxista do poder. Para além das relações de produção, há que indagar sobre as estruturas de oportunidade e a mobilização de recursos em contextos estruturais especificos de relações de poder e atendendo aos constrangimentos da economia política, procurando dotar as comunidades dos dominados e explorados de instrumentos analíticos que possam potenciar as formas de contra-poder e as reais possibilidades de mudança estrutural.

Esta possibilidade de mudança estrutural aparece em filigrana, mais como uma consequência do que como resultado de acções concertadas, na análise que faz Benjamin Tejerina dos movimentos sociais contemporâneos. Partindo da definição já clássica dos direitos de cidadania em T. H. Marshall, e usando como ilustração dados recolbidos junto de ecologistas na Espanha e reflexões teóricas sobre outros movimentos sociais na Europa e no Mundo, Tejerina assinala um duplo processo de crise: por implosão da cidadania e por explosão da política como espaço autónomo de diferenciação social. A implosão da cidadania poderá antever a formação de uma cidadania global ou planetária. A explosão da política obriga a repensar as tradicionais e ténues fronteiras entre o privado, o semi-público e o público. Cabe perguntar, então, até que ponto as esferas emergentes pós-privativas e pré-políticas, terrenos privilegiados da transformação pessoal e identitária, poderão ser portadoras de dinâmicas emancipadoras e transformadoras das desigualdades socioeconómicas.

Os outros textos deste número temático apresentam um cariz mais empírico. Fazem-no, contudo, a partir de perspectivas e de constatações distintas. Os 
artigos de Daniel Cefaï e de Ana Maria Seixas abordam um conjunto de protestos que se ancoram numa dimensão axiológica, enquanto as análises de José Manuel de Oliveira Mendes sobre um movimento social local e as do mesmo com Ana Maria Seixas sobre os protestos em Portugal no período de 1992 a 2002 nos devolvem um conjunto de acções marcadas pela exigência de direitos de cidadania basilares.

Para o caso francês, Daniel Cefaï faz uma descrição exaustiva e crítica da galáxia da contestação composta por centenas de movimentos de alter-globalização e que permitiram a produção e articulação de novos problemas públicos e o surgimento de novas arenas públicas. Radicando na reivindicação de um mundo alternativo, na assunção plena de cidadania em situação (atenda-se à mobilização dos "sem"), estes movimentos, muitas vezes lúdicos e festivos, não só permitem um leque variado de expressões simbólicas e identitárias como constroem novos espaços de sociabilidade e de relações sociais mais igualitárias. Para Cefaï, a questão central está em saber como estes movimentos podem potenciar verdadeiras mudanças nas relações de poder e configurar outras lógicas no campo político.

José Manuel de Oliveira Mendes e Ana Maria Seixas, a partir dos registos de imprensa, fazem uma descrição das lógicas e das dinâmicas de protesto em Portugal. Estamos perante processos localistas, centrados sobretudo na exigência de direitos básicos de cidadania, mas que revelam um potencial elevado de contestação e de presença nos espaços públicos e que se concretizam à margem dos poderes estabelecidos e dos aparelhos politico-partidários.

Essa relação complexa e ambígua com os partidos politicos e com os poderes instituídos é-nos restituida etnograficamente pelo estudo apresentado por José Manuel de Oliveira Mendes sobre um movimento social local. Com este artigo, apercebemo-nos das maneiras como se produz cidadania em contextos locais caracterizados por uma forte mobilização política, e da capacidade de subjectivação política das pessoas e das populações, em interaç̧ão permanente com o Estado e as instâncias de governação.

Por último, Ana Maria Seixas demonstra como, nas oscilações dos ciclos de protesto dos estudantes do ensino secundário em Portugal, em sintonia com os ciclos políticos e as políticas educativas, vemos emergir lógicas de contestação não só estratégicas mas também perpassadas por exigências de participação cívica e de afirmação de valores radicados no direito à educação e à qualidade do processo educativo.

José Manuel de Oliveira Mendes Ana Maria Seixas 